\title{
Lack of serological evidence for venereal spirochaetosis in wild Victorian rabbits and the susceptibility of laboratory rabbits to Treponema paraluis-cuniculi
}

\author{
S R GRAVES,* J W EDMONDS, $\uparrow$ AND ROSAMOND C H SHEPHERD + \\ From the *Microbiology Department, Monash University, Clayton, and the + Keith Turnbull Research \\ Institute, Frankston, Victoria, Australia
}

SUMMARY Sera from 608 wild rabbits were examined using serological tests for syphilis as an indicator of infection with Treponema paraluis-cuniculi. Only eight sera gave positive or weakly positive results in the rapid plasma reagin (RPR) test, and none of these eight sera gave positive results in the Treponema pallidum haemagglutination assay (TPHA). Thus, it appears that wild rabbit populations in Victoria, Australia, are not naturally infected with $T$ paraluis-cuniculi.

Normal Australian laboratory rabbits however were readily infected with $T$ paraluis-cuniculi, either by intradermal or intratesticular inoculation or by the venereal route. In the latter case, treponeme-containing lesions developed after about five months' cohabitation with infected mates. The disease was successfully transmitted from male to female and from female to male rabbits by the venereal route. In most cases infected rabbits became RPR-positive (17/19 rabbits) and in all cases TPHA-positive (19/19), indicating that serological tests for syphilis can be used to screen rabbits for this disease.

\section{Introduction}

Rabbit venereal spirochaetosis is a sexually transmitted bacterial disease caused by Treponema paraluis-cuniculi. It occurs in European wild and laboratory rabbits, Oryctolagus cuniculus (L), in laboratory rabbits in North America, and probably in European hares, ${ }^{1}$ Lepus europaeus (Pallus), but it has not been reported in Australia.

Rabbits are not native to Australia. They were introduced in the late eighteenth and nineteenth century as a result of European colonisation of the continent and became well established as a feral animal in Victoria during the 1860s. Although the predominant progenitors were wild-type rabbits, domestic rabbits contributed to the gene pool in several locations. ${ }^{2}$

$T$ paraluis-cuniculi is closely related, morphologically and antigenically, to Treponema pallidum, the causative agent of syphilis in man. ${ }^{3}$ Rabbits

Address for reprints: Dr S R Graves, Microbiology Department, Monash University Medical School, Alfred Hospital, Prahran, Victoria 3181, Australia

Received for publication 12 March 1980 infected with $T$ paraluis-cuniculi develop antibodies that can be detected using standard serological tests for syphilis. ${ }^{4}$ In this study sera taken from wild rabbits from various parts of Victoria were tested for treponemal antibodies using both a non-specific test for syphilis, the rapid plasma reagin (RPR) test, and a highly specific test for treponemal infection, the $T$ pallidum haemagglutination assay (TPHA).

Australian laboratory rabbits were also tested for their susceptibility to $T$ paraluis-cuniculi by intradermal, intratesticular, intraurethral, and venereal transmission, and the infections were followed clinically, bacteriologically, and serologically.

\section{Materials and methods}

Wild rabbits were collected from 19 areas* of Victoria. ${ }^{5}$ Blood was taken via the marginal ear vein from live rabbits and from the jugular vein or heart of shot rabbits. The serum was collected and stored frozen until required.

* Details of the areas surveyed can be obtained from the authors on request. 
SEROLOGICAL TESTS

The RPR test was carried out according to the manufacturer's instructions (Commonwealth Serum Laboratories, Melbourne, Australia). Results were recorded as strongly positive, weakly positive, or negative.

The TPHA was performed at Fairfield Hospital, Melbourne, or at Monash University, using the kit produced by Fujizoki Pharmaceutical Company Ltd. The manufacturer's instructions were followed. Only titres greater than 1/80 were considered positive and therefore indicative of past or current treponemal infection. Known positive and negative control sera were included in each test series.

\section{INFECTION WITH TPARALUIS-CUNICULI (LABORATORY RABBITS) \\ Intradermal inoculation}

$T$ paraluis-cuniculi (strain 8816) was obtained from the Center for Disease Control, Atlanta, Georgia, USA, by courtesy of Dr A Balows. It was sent to Australia in the frozen orchitic testis of a rabbit that had been infected intratesticularly. It has subsequently been maintained by intratesticular inoculation in rabbits or stored frozen $\left(-70^{\circ} \mathrm{C}\right)$ in an equal mixture of $30 \%$ glycerol in isotonic saline (prereduced) and $T$ pallidum maintenance medium. ${ }^{6}$ Male rabbits inoculated intradermally on the shaved back or intratesticularly were kept in individual cages at $16-19^{\circ} \mathrm{C}$ with antibiotic-free food and water in unlimited quantities.

\section{Venereal transmission}

In the venereal transmission experiments rabbits were kept in spacious open pens (completely surrounded with wire-mesh) at the Keith Turnbull Research Institute, Frankston, Victoria. They were fed antibiotic-free food and water and occasionally grass.
In the experiment to test male-to-female venereal transmission of $T$ paraluis-cuniculi one experimentally infected male rabbit (No 82673) was enclosed with four normal female rabbits. The male rabbit had been infected intratesticularly, intraurethrally, and under the prepuce (Table I) with a concentrated (approximately $10^{7} / \mathrm{ml}$ ) preparation of $\boldsymbol{T}$ paraluis-cuniculi obtained from frozen stocks in glycerol/medium. It was not possible to place more than one male rabbit in the pen with the females because of fighting between the males.

In the experiment to test female-to-male venereal transmission of $T$ paraluis-cuniculi one normal male rabbit (No 83324) was enclosed with the four female rabbits above after they had all become infected, as shown by the presence of treponeme-containing genital lesions. The previous male rabbit (No 82673) was removed at this stage.

\section{EXAMINATION FOR LESIONS}

Rabbits were examined at regular intervals for genital lesions. Genital scrapings were taken by gently abrading the surface of the lesion with a scalpel blade and adding drops of sterile saline (approximately $0.5 \mathrm{ml}$ ) from a Pasteur pipette. The exudate-saline mixture was collected in the same Pasteur pipette and examined by darkfield microscopy for the presence of treponemes. Blood samples were taken from the marginal ear vein and the serum examined for antibodies by the RPR test and the TPHA.

\section{Resuits}

WILD RABBITS

Of the 608 rabbit sera examined, only eight gave positive results in the RPR test, and of these four were weak reactions. These eight sera all gave negative results to the TPHA.

TABLE I Treponema paraluis-cuniculi infection in male laboratory rabbits with site of inoculation

\begin{tabular}{|c|c|c|c|c|c|}
\hline \multirow[b]{3}{*}{ Response to infection } & \multicolumn{5}{|c|}{ Rabbit No and site of inoculation } \\
\hline & 580 & 581 & 582 & 607 & 82673 \\
\hline & Testes & Testes & $\begin{array}{l}\text { Prepucel } \\
\text { urethra* }\end{array}$ & $\begin{array}{l}\text { Testes/ } \\
\text { prepuce/ } \\
\text { urethra }\end{array}$ & $\begin{array}{l}\text { Testes/ } \\
\text { prepuce/ } \\
\text { urethra }\end{array}$ \\
\hline $\begin{array}{l}\text { Orchitis } \\
\text { Transient granular surface lesions on testes }\end{array}$ & Yes & Yes & No & Yes & No \\
\hline $\begin{array}{l}\text { (treponemes present) } \\
\text { Erythematous lesions on prepuce and external genitalia }\end{array}$ & No & Yes & No & No & No \\
\hline $\begin{array}{l}\text { (treponemes present) } \\
\text { Spontaneous healing of lesions } \\
\text { RPR test (days after infection) } \\
\text { TPHA titre (days after infection) }\end{array}$ & $\begin{array}{l}\text { No } \\
+ \\
+ \\
t\end{array}$ & $\begin{array}{l}\text { Yes } \\
\text { Yes } \\
++(75) \\
1 / 640(137)\end{array}$ & $\begin{array}{l}\text { Yes } \\
\text { Yes } \\
+(195) \\
1 / 640(138)\end{array}$ & $\begin{array}{l}\text { No } \\
\text { Yes } \\
+(35) \\
1 / 1280(70)\end{array}$ & $\begin{array}{l}\text { Yes } \\
\text { Yes } \\
\pm(48) \\
1 / 1280(120)\end{array}$ \\
\hline
\end{tabular}

* Surface inoculation only; skin not broken

t Rabbit killed at height of orchitis to transfer bacterium

++ Very strongly positive; + strongly positive; \pm Weakly positive 
One of us (RCHS), having examined thousands of wild rabbits throughout Victoria, has never seen genital lesions resembling those of $T$ paraluiscuniculi as manifested in the venereally infected laboratory rabbits in this study. We therefore conclude that this disease is not present in wild Victorian rabbits.

\section{INFECTION WITH TPARALUIS-CUNICULI (LABORATORY RABBITS) \\ Intradermal inoculation}

Ten male rabbits, each inoculated intradermally at one site on their shaved backs with $2 \times 10^{7}$ viable treponemes, usually developed lesions by day 6 after inoculation, although in one (No 17) they took 55 days to develop (table II). The early lesions appeared as small areas of erythema and induration in the skin, which gradually enlarged. These early lesions were very similar to early $T$ pallidum lesions in rabbits. ${ }^{3}$ They reached their maximum size (usually $5-9 \mathrm{~mm}$ diameter induration) at various times between 10 and 136 days after inoculation (table II) and then regressed at varying rates. In four of the rabbits the lesions disappeared between 55 and 70 days after inoculation; in another two at about 218 days and in another three the lesions were still present 365 days after inoculation, at the end of the observation period.

Both the RPR test and TPHA gave positive results 84 days after inoculation, indicating that the infection had stimulated both a specific and nonspecific antibody response in the rabbits.

As the dermal lesions faded they became less indurated with a smaller zone of erythema. In most cases the lesion surface became granular and crumbled on gentle abrasion. In three rabbits (Nos 14,21 , and 23) secondary (or satellite) lesions formed around the original lesion 202,149 , and 246 days after inoculation. In all cases they were considerably smaller than the original lesion. These three rabbits still had their original lesion 365 days after inoculation and the development of secondary lesions probably represented a poor or slow development of immunity. In one rabbit the four satellite lesions healed before the end of the observation period whereas in the other two they were still present.

\section{Other sites of inoculation}

In this study two rabbits were inoculated intratesticularly, two intratesticularly, intraurethrally, and under the prepuce, and one intraurethrally and under the prepuce, care being taken not to pierce the skin in the latter case.

All five rabbits became infected and the four rabbits tested by the RPR test and TPHA developed antibodies (table I). The location of the lesions varied depending partly on the site of infection (table I), but in all cases the lesions healed spontaneously. Rabbits Nos 607 and 82673 were capable of producing normal offspring. The other three rabbits were not tested.

\section{Male-to-female venereal transmission}

Male rabbit No 82673 developed treponeme-positive genital lesions after intratesticular, intraurethral, and sub-preputial inoculation with viable $T$ paraluiscuniculi from frozen material. Immediately after inoculation he was placed in a pen with four normal serologically negative female rabbits (Nos 658, 91326,91249 , and 21271) to ascertain whether or not he would transmit the infection to the female rabbits. All rabbits were examined at monthly intervals.

TABLE II Treponema paraluis-cuniculi infection in male laboratory rabbits infected intradermally with $2 \times 10^{7}$ treponemes on the shaved back

\begin{tabular}{|c|c|c|c|c|c|c|c|c|c|c|}
\hline \multirow[b]{2}{*}{ Response to infection } & \multicolumn{10}{|c|}{ Rabbit No } \\
\hline & 104 & 23 & 15 & 14 & 939 & 940 & 21 & 22 & 17 & 16 \\
\hline \multirow{5}{*}{$\begin{array}{l}\text { Latent period of infection (days)* } \\
\text { Maximum size (diameter) of } \\
\text { indurated lesion (mm) } \\
\text { Time after inoculation when lesion } \\
\text { most strongly indurated (days) } \\
\text { Time after inoculation when lesions } \\
\text { fully regressed (days) } \\
\text { RPR test at } 84 \text { days after inoculation } \\
\text { TPHA at } 84 \text { days after inoculation } \\
\text { (titre) }\end{array}$} & 6 & 6 & 6 & 6 & 6 & 20 & 55 & 8 & 10 & 6 \\
\hline & 6 & 9 & 18 & 6 & 6 & $\pm \S$ & 5 & 8 & 7 & 7 \\
\hline & 14 & 41 & 84 & 14 & 20 & $41^{* *}$ & 136 & 10 & 55 & 10 \\
\hline & $\begin{array}{l}55 \\
+\end{array}$ & $\begin{array}{l}>365 t \\
\pm\end{array}$ & $\begin{array}{l}>178 \neq \\
++\end{array}$ & $\begin{array}{l}>365 t \\
+\end{array}$ & $\begin{array}{l}218 \\
++\end{array}$ & $\begin{array}{l}70 \\
+\end{array}$ & $\begin{array}{l}>365 t \\
\pm\end{array}$ & $\begin{array}{l}70 \\
+\end{array}$ & $\begin{array}{c}218 \\
+\end{array}$ & $\begin{array}{l}70 \\
\pm\end{array}$ \\
\hline & $1 / 640$ & $1 / 1280$ & $>1 / 5120$ & $1 / 1280$ & $>1 / 5120$ & $1 / 640$ & $1 / 640$ & $1 / 1280$ & $1 / 1280$ & $1 / 640$ \\
\hline
\end{tabular}

* Time between inoculation and first appearance of lesion

** Time of maximum zone of erythema (not induration) as lesion was only slightly indicated

$\dagger$ Experiment terminated at 365 days: lesions still present

₹ Rabbit destroyed at 178 days because of intercurrent ear infection

$\S$ Very slight induration with a maximum zone of erythema of $18 \mathrm{~mm}$ diameter

++ Very strongly positive; + strongly positive; \pm weakly positive 
The female rabbits developed genital lesions containing large numbers of treponemes about five months later (table III). The lesions developed as generalised inflammation and oedema of the labia, which later became crusted. It was not possible to quantify them. In all four rabbits lesions were transient even though treponemes could be readily isolated from the labial epidermis and mucosa by gentle scraping (table III), indicating that a rabbit may be infected and infectious without showing obvious lesions. Six months after cohabitation with the infected male all four female rabbits had developed specific antitreponemal antibodies, as shown by a positive TPHA titre, and three had also developed non-specific antibodies, as detected by the RPR test. One of the female rabbits (No 91249) may have been spontaneously cured by 10 months, when no lesions were seen and treponemes were not found in scrapings. This is uncertain however as the observation was terminated at that time.

TABLE III Treponema paraluis-cuniculi infection in four female laboratory rabbits after cohabitation with an infected male rabbit

\begin{tabular}{|c|c|c|c|c|}
\hline \multirow[b]{2}{*}{ Response to infection } & \multicolumn{4}{|c|}{ Rabbit No } \\
\hline & 658 & 91326 & 91249 & 91271 \\
\hline \multicolumn{5}{|l|}{ Latent period of } \\
\hline infection (months) ${ }^{*}$ & 3 & 6 & 5 & 5 \\
\hline \multicolumn{5}{|c|}{$\begin{array}{l}\text { Treponemes present in } \\
\text { genital lesions or labial } \\
\text { scrapings taken at: }\end{array}$} \\
\hline 6 monthst & + & + & + & + \\
\hline 7 months & + & $+\neq$ & + & + \\
\hline 8 months & + & - + & + & $+\neq$ \\
\hline 9 months & $+\neq$ & + & + & $+\neq$ \\
\hline 10 months & + & + & $-\neq$ & + \\
\hline \multicolumn{5}{|l|}{ RPR test result at: } \\
\hline 6 months & \pm & - & \pm & \pm \\
\hline 8 months & + & - & + & + \\
\hline 10 months & ++ & - & ++ & \pm \\
\hline \multicolumn{5}{|l|}{ TPHA titre at: } \\
\hline $\begin{array}{l}6 \text { months } \\
8 \text { months }\end{array}$ & $1 / 5120$ & $\begin{array}{l}1 / 640 \\
1 / 1280\end{array}$ & $\begin{array}{r}>1 / 5120 \\
1 / 1280\end{array}$ & $\begin{array}{l}1 / 320 \\
1 / 320\end{array}$ \\
\hline 10 months & $1 / 5120$ & $1 / 1280$ & $1 / 640$ & $1 / 640$ \\
\hline
\end{tabular}

* Period between cohabitation with male rabbit and the development of genital lesions containing treponemes

† Infected male rabbit 82673 removed at 6 months and normal male rabbit 83324 placed in the pen to detect female-to-male venereal transmission

₹ No macroscopically visible genital lesions present

++ Very strongly positive; + strongly positive; \pm weakly positive RPR test: - negative

\section{Female-to-male transmission}

The four venereally infected female rabbits (Nos 658, 91326, 91249, and 91271), with treponeme-containing genital lesions after six months' cohabitation with the originally infected male rabbit (table III), were placed in a pen with one normal male rabbit (No 83324). This male rabbit was also examined monthly. He developed treponeme-containing genital lesions after five months' cohabitation with the four infected female rabbits, when the TPHA gave a positive result at a titre of $1 / 320$ but the result of the RPR test was negative. Observations were terminated at that time as proof of venereal transfer had been obtained.

\section{Reproductive abilities}

Male rabbits, infected intratesticularly with $T$ paraluis-cuniculi, were able to sire normal healthy litters. Female rabbits, infected venereally, were also able to produce apparently healthy offspring. Two such kittens of infected mothers were examined serologically and found to have negative results to the RPR test even though the mother had treponemal antibodies.

\section{Discussion}

For many years rabbits have been used for research into human syphilis, primarily because they were susceptible to the human pathogen $T$ pallidum and the disease closely resembled primary syphilis in man. It was not until 1912 however that Ross ${ }^{7}$ suggested that the anogenital lesions seen in some rabbits may represent a spirochaetal infection. Bayon ${ }^{8}$ examined these lesions and found spirochaetes 8-12 $\mu$ in length, with 5-8 spirals, which were indistinguishable from $T$ pallidum. He concluded that this previously unrecognised spontaneous spirochaetal disease of rabbits may be a source of error in experiments on human syphilis in the rabbit. Several papers have reviewed the history of work on this disease $\mathrm{s}^{910}$ and several give extensive clinical and histological details of the disease after natural and artificial infection. ${ }^{411-14}$

The disease is apparently widespread in European wild and laboratory rabbits, North American laboratory rabbits, and European hares, ${ }^{1}$ although there are no reports of it being present or absent in other parts of the world. On the basis of our serological survey of Victorian rabbits we tentatively conclude that the disease is absent from Australia. The reason for this must presumably be that the rabbits which became successfully established as feral populations were free of the disease, either because the introduced rabbits were carefully selected or fortuitously. It is unlikely that a disease which does not cause rabbits to become systemically ill would have resulted in their keepers killing them off on the long sea voyage to Australia. There are other instances of parasites of European wild or domestic rabbits which either did not arrive or failed to become established in Australia, for example, Spilopsyllus cuniculi, the European rabbit flea, ${ }^{15}$ and Encephalitozoon cuniculi. ${ }^{16}$ On the basis of a study of sera from 20 Victorian hares which gave negative serological results treponemal disease is probably 
absent from this population also, although $27 \%$ of European hares had positive serological results for syphilis. ${ }^{1}$

The reported incidence of rabbit venereal spirochaetosis in naturally infected populations varies considerably. McLeod and Turner ${ }^{14}$ found only six rabbits out of 1800 with treponeme-containing genital lesions in a survey of North American laboratory rabbits. Fried and Orlov ${ }^{17}$ reported on two epidemics of rabbit venereal spirochaetosis in Moscow in 1927 and 1928 . Only $0.7 \%$ of rabbits less than 8 months old were infected whereas $46.4 \%$ of rabbits older than 1 year were infected, suggesting its venereal mode of transmission. Artz and $\mathrm{Kerl}^{18}$ found an incidence of $26.9 \%$ in adult European rabbits and Noguchi ${ }^{11}$ reported incidences of $10 \%$ and $30 \%$ in North American laboratory rabbits. Adams et al $^{13}$ reported the disease to be endemic in British wild and hutch rabbits and found 14 of 228 laboratory rabbits with treponeme-containing genital lesions. He further added that "reputable observers" estimated that $10-40 \%$ of wild rabbits were affected.

Other surveys have been based on serological methods using tests designed for the diagnosis of human syphilis. A number of these reports are recorded by Smith and Pesetsky ${ }^{9}$ using non-specific tests such as the Wassermann reaction and the Venereal Disease Research Laboratory (VDRL) test, both of which detect antibody to cardiolipin, as does the RPR test used in our study.

There is considerable difference of opinion on whether or not the disease gives rise to positive results to cardiolipin tests; some argue that it does ${ }^{4} 1920$ while others have found their results to be uniformly negative. ${ }^{11} 12$ Our controlled experiments with venereally and experimentally infected rabbits may have settled this controversy. While most rabbits $(17 / 19)$ did develop positive results to the RPR test, two did not (rabbits Nos 91326 and 83324), although treponeme-containing genital lesions were present. The result is obviously variable. With the more specific (and probably more sensitive) TPHA however all rabbits with lesions gave positive results $(19 / 19)$. This is a fairly recent test and has not previously been used in rabbit venereal spirochaetosis. Other specific antitreponemal serological tests however have been used. Pannu et $a^{20}$ studied 30 normal rabbits, 10 of which had a positive VDRL test result, and found two had weakly reactive results to the fluorescent treponemal antibody absorbed (FTAABS) test, although in one case the result subsequently became non-reactive. Twenty-nine of $\mathbf{3 0}$ rabbits gave negative results to the Treponema pallidum immobilisation (TPI) test and the result on the other rabbit was not stated in the paper. There was no clinical or bacteriological evidence however that these rabbits were infected. Small and Newman ${ }^{4}$ detected positive FTA-ABS test results in known infected rabbits with peak titres at the time of appearance of cutaneous lesions. They also detected positive RPR test results in all infected rabbits in contrast to our own observations. Significant titres (in the RPR and FTA-ABS tests) were present six months after inoculation at the end of their experiment.

In retrospect it appears that it may have been wiser to screen the wild Victorian rabbit sera with the TPHA rather than with the RPR test as the former gave uniformly positive results in infection. The RPR test was used however because it is generally considered to be the appropriate screening test in serological surveys of syphilis. Nevertheless, it is unlikely that our conclusions on the absence of this disease in wild Victorian rabbits would be altered by retesting all sera with the TPHA. The eight RPR-positive (or weakly positive) sera were all TPHA-negative and these are the sera most likely to have been from $T$ paraluis-cuniculi infected rabbits.

Our demonstration of venereal transmission of $T$ paraluis-cuniculi between rabbits was not new; others have previously done so. ${ }^{11-13}$ However, our experiments did show that Australian laboratory rabbits were readily susceptible to this bacterium and that the absence of infection in the wild population, including rabbits known to be partly domestic in origin, is probably not due to innate rabbit resistance to the disease but to a failure of the pathogen to be introduced.

Our observation that $T$ paraluis-cuniculi could be readily isolated from labial scrapings in infected female rabbits, even in the absence of microscopic lesions, has also been reported. ${ }^{13}$ While our rabbits developed genital lesions about five months after cohabitation with infected mates, Noguchi ${ }^{11}$ reported that a male rabbit developed lesions after three months in a similar situation. These time periods are not significantly different.

Two of the offspring of an infected, serologically positive female rabbit were themselves RPR-negative and apparently normal in every respect. This suggests that the infection did not become systemic and that a bacteraemia was not established, supporting earlier observations. ${ }^{12}{ }^{13}$ In general, maternal rabbit antibodies of any immunoglobulin class will pass into the fetal circulation, ${ }^{21}$ so our failure to detect antibodies reacting in the RPR test in these newborn rabbits is difficult to understand.

We wish to thank Mr Ian McLean and Mr Chris Roberts for their excellent technical assistance.

This work was supported by grants from the National Health and Medical Research Council, the 
Utah Foundation, the Danks Trust, the estate of the late George Adams, the Ian Potter Foundation, and Monash University, from whom funds are gratefully acknowledged. The collection of sera was supported by the Wool Research Trust Fund.

\section{References}

1. Horvath I, Kemenes F, Molnar L, Szeky A, Racz I. Experimental syphilis and serological examination for treponematosis in hares. Infect Immun 1980; 27:231-4.

2. Edmonds JW. Immunoglobulin allotypes of wild rabbits Oryctolagus cuniculus (L) in south-eastern Australia. Thesis, Melbourne, Australia: Monash University, 1977.

3. Turner TB, Hollander DH. Biology of the treponematoses. World Health Organization Monograph Series No. 35, Geneva: WHO, 1957.

4. Small JD, Newman B. Venereal spirochetosis of rabbits (rabbit syphilis) due to Treponema cuniculi; a clinical, serological and histopathological study. Lab Anim Sci 1972;22:77-89.

5. Shepherd RC, Nolan IF, Edmonds JW. A review of methods to capture live wild rabbits in Victoria. Journal of Wildlife Management 1978; 42: 179-84.

6. Graves S, Sandok P, Johnson R, Jenkin H. Retention of motility and virulence of Treponema pallidum (Nichols strain) in vitro. Infect Immun 1975; 12: 1116-20.

7. Ross EH. An intracellular parasite developing into spirochaetes. $\mathrm{Br}$ Med J 1912; ii: 1651-4.

8. Bayon $\mathrm{H}$. A new species of treponema found in the genital sores of rabbits. $\mathrm{Br}$ Med J 1913; ii: 1159.
9. Smith JL, Pesetsky BR. The current status of Treponema cuniculi; review of the literature. $B r J$ Vener Dis 1967; 43:117-27.

10. Smith JL. In: Spirochaetes in Late Seronegative Syphilis, Penicillin Notwithstanding. Springfield, Illinois, USA: Charles C Thomas, 1969: 156-75.

11. Noguchi H. Venereal spirochaetosis in American rabbits. J Exp Med 1922; 35:391-407.

12. Warthin AS, Buffington E, Wanstrom RC. A study of rabbit spirochetosis. J Infect Dis 1923;32:315-32.

13. Adams DK, Cappell DF, McCluskie JA. Cutaneous spirochaetosis due to Treponema cuniculi in British rabbits. Journal of Pathology and Bacteriology 1928;31: 157-61.

14. McLeod C, Turner TB. Studies on the biologic relationship between the causative agent of syphilis, yaws and venereal spirochaetosis of rabbits. I Observations on Treponema cuniculi infections in rabbits. Am J Syphilis 1946;30:442-54.

15. Sobey WR, Conolly D. Myxomatosis: the introduction of the European rabbit flea (Spilopsylius cuniculi Dale) into the wild rabbit populations in Australia. J h:g Camb 1971;69:331-46.

16. Cox JC, Pye D, Edmonds JW, Shepherd RC. An investigation of Encephalitozoon cuniculi in the wild rabbit Oryctolagus cuniculus in Victoria. J Hyg Camb 1980;84:295-300.

17. Fried SM, Orlov SS. Spontaneous spirochaetosis and experimental syphilis in rabbits. Archives of Dermatology and Syphilology (Chicago) 1932; 25: 893-905.

18. Arzt L, Kerl W. Weitere mitteilung über spirochätenhesunde bei kaninchen. Wien Klin Wochenschr 1914;27:1053-5.

19. Clark JW. Serological tests for syphilis in healthy rabbits. $\mathrm{Br} J$ Vener Dis 1970;46:191-7.

20. Pannu JS, Rosenberg MA, Israel CN, Smith JL. Incidence of reactive VDRL tests in the normal rabbit. In: Smith JL, ed. Spirochaetes in Late Seronegative Syphilis, Penicillin Notwithstanding. Springfield, Illinois, USA: Charles C Thomas, 1969: 176-8.

21 Beer AE. Billingham RE. The Immunology of Mammalian Reproduction. Eaglewood Cliffs, New Jersey, USA: Prentice Hall Inc, 1976 